\title{
The Effects of Private Health Insurance on Universal Health Coverage Objectives in China: A Systematic Literature Review
}

\author{
Runguo $\mathrm{Wu}^{1,2, *}$, Niying $\mathrm{Li}^{3}$ (i) and Angelo Ercia ${ }^{4}$ \\ 1 Institute of Population Health Sciences, Barts and The London School of Medicine and Dentistry, Queen \\ Mary University of London, London E1 2AB, UK \\ 2 Global Health Policy Unit, School of Social and Political Science, University of Edinburgh, \\ Edinburgh EH8 9LD, UK \\ 3 School of Pharmacy, University of Wisconsin-Madison, Madison, WI 53705, USA; nli59@wisc.edu \\ 4 Division of Informatics, Imaging \& Data Sciences, School of Health Sciences, the University of Manchester, \\ M13 9PL Manchester, UK; aenercia06@gmail.com \\ * Correspondence: r.wu@qmul.ac.uk; Tel.: +44-78-5745-6195
}

Received: 17 February 2020; Accepted: 17 March 2020; Published: 19 March 2020

\begin{abstract}
Background: We conducted a systematic review on the role of private health insurance to complement the social health insurance system towards achieving universal health coverage in China. This review presents the impacts of private health insurance on expanding coverage, increasing access to healthcare, and financial protection. Methods: A systematic review was conducted by searching peer-reviewed articles published between January 2000 and March 2018 in Web of Science, PubMed, and China Knowledge Resource Integrated Database. The search terms included coverage prevalence, access and financial protection related to private health insurance in China. A total of 31 studies were selected. Results: Coverage prevalence of private health insurance gradually increased but it was unequally distributed across regions and populations. The expansion of social health insurance has enhanced the total aggregate premium of private health insurance but has had a mixed impact on the take-up of private health insurance. Private insurance beneficiaries were found to limit their utilisation of healthcare services and there was no evidence that it ensured financial protection. Conclusion: The role of private health insurance (PHI) in extending universal health coverage in China was limited and therefore should not be overstated.
\end{abstract}

Keywords: private health insurance; healthcare financing; universal health coverage; China; access to healthcare; financial protection

\section{Introduction}

In the early 2000s, the Chinese government began to increase spending to expand the social health insurance system (SHI) after two decades of retrenchment. The public spending as the share of total healthcare expenditure in 2003 was $36.2 \%$ and increased to $56 \%$ by 2012 [1], which mostly came in the form of subsidisation for SHI contributions [2,3]. The increase in subsidies enabled people to gain coverage primarily from SHI schemes. Analysis of national data suggests that the overall health insurance coverage increased from 29.7\% to 95.7\% between 2003 and 2011 [4]. The three main SHI schemes in China-the Urban Employees' Basic Medical Insurance (UEBMI), the Urban Residents' Basic Medical Insurance (URBMI) for UEBMI-uncovered urban registrants, and the New Cooperative Medical Scheme (NCMS) for rural registrants-covered around $87 \%$ of the population [5]. Furthermore, government subsidies enabled coverage benefits to expand services in inpatient care, outpatient care, treatment of acute illness, and treatment of chronic disease [6]. 
Despite the development, many households are exposed to healthcare-related financial risks as SHI policies have limited coverage for treatment and prescriptions, co-payments, deductibles, and limited reimbursement [6] (Table 1). The annual incidence of catastrophic health expenditure continued to increase from 2003 at 12 to $12.9 \%$ in 2011 [4]. Furthermore, almost one-third of total health expenditure still came from out-of-pocket payments in 2013 [7].

Table 1. Summary of China's social health insurance institutions ${ }^{1}$.

\begin{tabular}{|c|c|c|c|}
\hline SHI Schemes $^{2}$ & UEBMI & NCMS & URBMI \\
\hline Year of launch & 1998 & 2003 & 2007 \\
\hline Administration department & $\begin{array}{l}\text { Human Resource and Social } \\
\text { Security }\end{array}$ & Health & $\begin{array}{l}\text { Human Resource and } \\
\text { Social Security }\end{array}$ \\
\hline Target population & Urban employees & Rural registrants & Urban registrants without UEBMI \\
\hline Pooling level & Prefecture & County & Prefecture \\
\hline Number of pools & 333 & 2852 & 333 \\
\hline Enrolment & Compulsory & Voluntary & Voluntary \\
\hline Number of members & 265 million & 805 million & 272 million \\
\hline Individual contribution & $2-3 \%$ of salary & $¥ 30-50$ & $¥ 30-50$ \\
\hline $\begin{array}{c}\text { Employer/government } \\
\text { contribution }\end{array}$ & $6-8 \%$ of salary & $¥ 200$ & $¥ 200$ \\
\hline Inpatient reimbursement rate & $81 \%$ & $<50 \%$ & $64 \%$ \\
\hline Outpatient reimbursement rate & Depends on MSA & $0-40 \%^{3}$ & $0-40 \%^{3}$ \\
\hline Reimbursement cap & Six-times local average wage & $\begin{array}{l}\text { Eight-times local } \\
\text { peasants' income }\end{array}$ & Six-times local disposable income \\
\hline
\end{tabular}

${ }^{1}$ Based on 2011-2012 data. ${ }^{2}$ SHI = social health insurance; UEBMI = Urban Employees' Basic Medical Insurance; NCMS = New Cooperative Medical Scheme; URBMI = Urban Residents' Basic Medical Insurance; FMS = Free Medical Scheme; MSA = UEBMI's individual medical savings account. ${ }^{3}$ An approximate estimate as the coverage of NCMS and URBMI gradually expanded and varied spatially; the data about UEBMI, NCMS, and URBMI refer to $[3,6,8-11]$.

Private health insurance (PHI) was introduced in China during the economic reforms of the 1980s. The Chinese government has increasingly considered the role of PHI as a financial source to its health system and address the coverage gap within the current SHI system $[4,6]$. Theoretically, the expansion of PHI could improve the current SHI by 1) being a substitute form of health coverage for individuals that are unable to get coverage from an SHI scheme; and 2) being a complementary and supplementary coverage for individuals covered by a plan in the SHI scheme. PHI prevalence was initially low and limited to corporate customers, who bought PHI for their employees. Since the mid-1990s, demand for PHI increased and more commercial insurers entered [12]. In 2003, there were only around three hundred PHI products in the market and no specialised PHI companies [12], while in 2013, more than one hundred commercial insurers and five specialised PHI companies operated PHI business, providing thousands of products [13].

In recent years, the PHI market has rapidly grown in terms of total aggregate premium income, whereas its compensation long accounted for a minor part of total health expenditure (Figure 1). Government officials especially aim to support SHI and PHI to become mutually reinforcing, such that PHI helps SHI to fill the gaps in coverage depth and height, and in turn the SHI expansion boosts the PHI market by increasing the awareness of the importance of health insurance and leaving sufficient room for PHI operation [13-15]. For example, the government has encouraged employers to purchase PHI for their employers in addition to being under the UEBMI scheme of SHI and implemented regulations to simplify the compensation process between PHI insurers and local SHI agencies [16]. Most recently, the government has offered tax incentives for employers and individuals purchasing PHI through a series of pilot programmes in several major urban centres [17].

While the Chinese government has increasingly considered extending the role of PHI, there are ongoing debates among global health scholars and policymakers over its effectiveness in expanding coverage and supporting the principles of universal health coverage (UHC). There is uncertainty on how effectively PHI can address the three dimensions of UHC with regards to the breadth (covered population), depth (covered benefits) and height (covered costs) of coverage [18]. An argument about the weakness of PHI's ability to expand coverage is its principle that aims to meet demand-a 
combination of willingness and capacity to pay, which may put low-income populations at risk of not being able to obtain PHI coverage due to their inability to pay [19]. Certain groups might also be given risk-rated premiums, causing it to be unaffordable for this population to maintain and sustain their coverage [20].

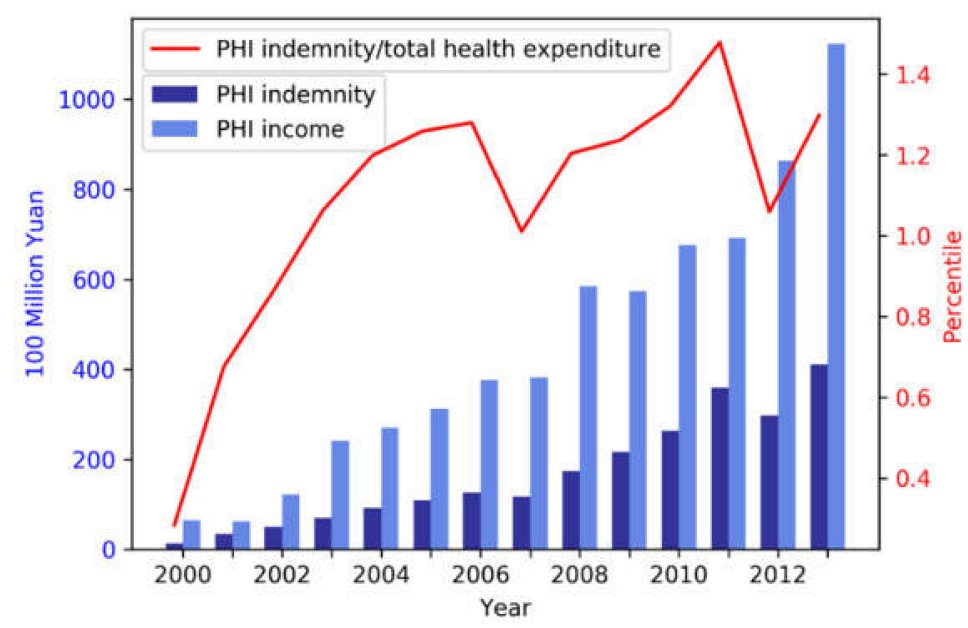

Figure 1. Income and indemnities of private health insurance (PHI), and the share of PHI indemnities in total health expenditure in China. Data source: Yearbook of China's Insurance 2014 (1 yuan or $¥ 1 \approx$ US $\$ 0.14$ at the current exchange rate. The following conversations referred to this rate).

Furthermore, the PHI market is vulnerable to market failures such as moral hazard and adverse selection. Moral hazard may contribute to patients using sub-optimal high levels of care, and physicians to prescribe unnecessarily expensive medications and more intensive treatments [21,22]. Insurers respond to moral hazard through co-payments and/or deductibles, therefore putting beneficiaries at risk for limited financial protection [23]. Adverse selection occurs as insurers have inaccurate information about the health status of enrolees. Insurers may set premiums based on average risks across the population (the community rating) [23]. The premium will be worth paying only for those with above average health risks, and therefore insurers may set the higher premium than the community rating, resulting in greater adverse selection. These factors may limit PHI's ability to meeting principles of universal coverage [21,24], and could even exacerbate inequities in the society [25].

Advocates of PHI contend that PHI can potentially meet the goal of a social health insurance system to address current existing coverage gaps [26,27]. By introducing a different source of funding into the health system, the government can then better allocate resources to the population, improve weak administrative capability in the public sector [28], and solve limited public fiscal space for SHI [29]. They also argue that PHI is affordable to those who already rely on out-of-pocket payments for healthcare [24], and government subsidies can help those who cannot afford PHI [26]. The World Health Organization (WHO) and the World Bank have ambiguous views on extending coverage through PHI. They believe that PHI can contribute to expanding coverage prevalence and laying foundation for national insurance, but they also note its limitations [30].

In China, there have been some studies that associated PHI's ability to address one or two issues with coverage gaps $[14,31,32]$. However, there is inconclusive evidence that suggest PHI can effectively extend overage and meet UHC principles. The purpose of our study was to conduct a systematic review that synthesises empirical evidence about PHI's ability to play a role in financing China's healthcare system and meet UHC principles. The review specifically focuses on understanding the role of PHI to expand coverage (in presence of expanding SHI), improve access to care, and provide financial protection. The current studies about PHI are still insufficient and fragmented. No study specifically and empirically associated the impacts of PHI with the three principles of UHC, and to our 
knowledge, no peer-reviewed systematic review on this topic has yet been published. To fill this gap, the review attempts to provide a broader understanding of how PHI have contributed to or limitedly contributed to these coverage targets by synthesising existing empirical evidence about $\mathrm{PHI}$ in China.

\section{Materials and Methods}

\subsection{Search Strategy}

This review focused on understanding the impacts of PHI on the UHC principles: Coverage prevalence, access to care, and financial protection [18]. The PRISMA guideline for systematic reviews [33] was adopted to design the search for peer-reviewed research articles in both English and Chinese that were published between January 2000 and March 2018. Three databases were selected: Web of Science (all databases), PubMed, and the China Knowledge Resource Integrated Database (CNKI), which is the largest, and most frequently updated database of Chinese-language academic publications.

We used the following search terms for all three synonyms of private health insurance in English: Private medical insurance, commercial health insurance, and commercial medical insurance. The terms used to refer to PHI in China were shangye Jiankang baoxian, and shangye yiliao baoxian. For the two English-language databases, the keyword "China" was included with each of the three search terms. This was not necessary for searches conducted in the CNKI database as all identified studies from CNKI are China-related.

Literature search was divided into three parts: 1) The coverage prevalence of PHI in China (including the impact of SHI on PHI coverage prevalence), 2) the effect of PHI on access to healthcare in China, and 3) the financial protection afforded by PHI in China. For coverage prevalence, the search terms were "prevalence", "demand", and "coverage" in English, and "xuqiu" (demand) or "fugai" (coverage) in Chinese. For access, the search terms were "access" or "utilisation/utilization" in English, and "keji" (access), "fuwu shiyong/liyong)" (service utilisation), "fuwu xuqiu" (service demand), "jiuyi" (using medical care), or "zhiliao" (treatment) were used in CNKI. For financial protection, the search terms "expenditure", "expense", "spending", "payment", or "cost" were used in the English language databases, while "zhichu" (expenditure), "huafei" (a less formal synonym of expenditure), "feiyong" (cost), and "jingjifudan" (financial burden) were used in CNKI. In addition, the citations of the included papers were scanned. If an article with a relevant title was cited but not identified in this search, it was added to the final review list after checking its eligibility using the criteria below.

The search strings used in Web of Science are presented here as an example of the searches used across the listed databases:

Search One: TS $=($ (health OR medical) AND (private OR commercial) AND (insurance china) AND (prevalence OR demand OR coverage));

Search Two: TS = ((health OR medical) AND (private OR commercial) AND (insurance china) AND (utilization OR utilisation OR access));

Search Three: TS $=($ (health OR medical) AND (private OR commercial) AND (insurance china) AND (expenditure OR expense OR spending OR payment OR cost)).

\subsection{Inclusion and Exclusion Criteria}

The following are the inclusion criteria for the studies selected for this review: (1) Empirical studies that were related to at least one of the three aspects of PHI, (2) that were conducted in China/Chinese health system, (3) that provided clear and full information of research design and methods, 4) that occurred between January 2000-March 2018, (5) and that were written in English and Chinese. The following are the exclusion criteria for the studies selected for this review: (1) Studies that examined willingness to buy PHI rather than enrolment or purchase, 2) that were based on tertiary data (i.e., those derived from other studies' outcomes of analysing primary or secondary data) were not included, in order to avoid citing the same study repeatedly, (3) that did not examine one of the 
three aspects, i.e., coverage prevalence, access to care, and financial protection, (4) or that are editorials, commentaries, conference abstracts, book chapters, and discursive essays. Full text of the remaining papers was screened to exclude those that do not meet the inclusion criteria.

\subsection{Quality Assessment and Risk of Bias}

Two reviewers (R.W. and N.L.) independently assessed the quality of the studies included in the review using a quality-graded protocol with a 10-point scale system (see Appendix A). This appraisal tool was adapted from existing tools in previous relevant studies [34-37], and handbooks of systematic review $[38,39]$ to suit this study. Appraisal results from two reviewers were compared. If the difference in the appraisal has no more than 1 point, then the average point was taken. The two reviewers discussed studies that had more than 1-point difference to reach consensus. Studies that were appraised as being low quality (0-3.5 points) were considered to have high risk of bias and therefore excluded from the review. Only studies that were appraised as being medium (4-6 points) and high (6.5-10 points) quality were reviewed in the study. The supplemental document (Table S1) provides a more detailed account of the appraisal process. Risk of bias across studies was considered. Since for many of the reviewed studies, PHI is not their only research objective, and thus the result about PHI may not be crucial to publication, the publication bias on PHI should be moderate. To minimise the bias, we not only reviewed the text of included articles but also directly scanned all result tables and appendices to make sure all data about PHI, regardless of statistical significance, were extracted. This could avoid the omission of data about PHI that either do not have statistical significance or do not interest the authors.

\section{Results}

\subsection{Characteristics of Included Studies}

The initial search identified 692 studies (Figure 2). Forty-four studies met the inclusion criteria. Of the 44 included studies, the average score of the quality assessment was 5.10 out of 10 points. From the quality assessment, 16 were categorised as high-quality studies, 15 as medium-quality studies, and 13 as low-quality studies. All the low-quality studies were removed and a total of thirty-one studies were included in the review. Among the 31 studies, 24 studies examined the prevalence and distribution of PHI coverage (including 14 examined the relationship between $\mathrm{PHI}$ and $\mathrm{SHI}$ ), 10 examined the effects of PHI on access to care, and nine examined the financial impacts of PHI (some studies are counted more than once due to engaging in more than one aspects of this review). For details of all these reviewed studies and the quality assessment results, see Table A1 (Appendix B).

Furthermore, 20 studies presented individual-level evidence, which focused on individuals' behaviour of obtaining PHI, and individual use of healthcare or spending on healthcare. Nine studies used the China Health and Nutrition Survey (CHNS), an ongoing longitudinal household national survey that commenced in 1989. Five studies used the China Health and Retirement Longitudinal Study (CHARLS), a longitudinal national study that started in 2008 and became nationwide in 2011 and included people aged 45 and above. Two studies used the State Council's URBMI Household Survey, ranging from 2007 to 2010; one used the Chinese Longitudinal Healthy Longevity Survey (CLHLS) that began in 1998 and studied people aged 65 years and above. The other studies used data from ad hoc, one-off surveys, most of which were primary data. Additionally, 11 studies focused on aggregate level evidence. The most common data source used were provincial-level statistics provided by government departments. Another source of aggregate data was from the National Health Service Survey (NHSS), which provides the county-level data.

Nine individual-level studies examined longitudinal data, and the other 11 individual-level studies examined cross-sectional data. In terms of aggregate-level studies, all but one examined longitudinal data. All survey databases used in these studies, including CHNS, CHARLS, NHSS, the URBMI survey, CLHLS and government provincial-level statistics, included multiple Chinese 
provinces. For one-off surveys, the scope of data collection varied depending on the objectives of the studies.

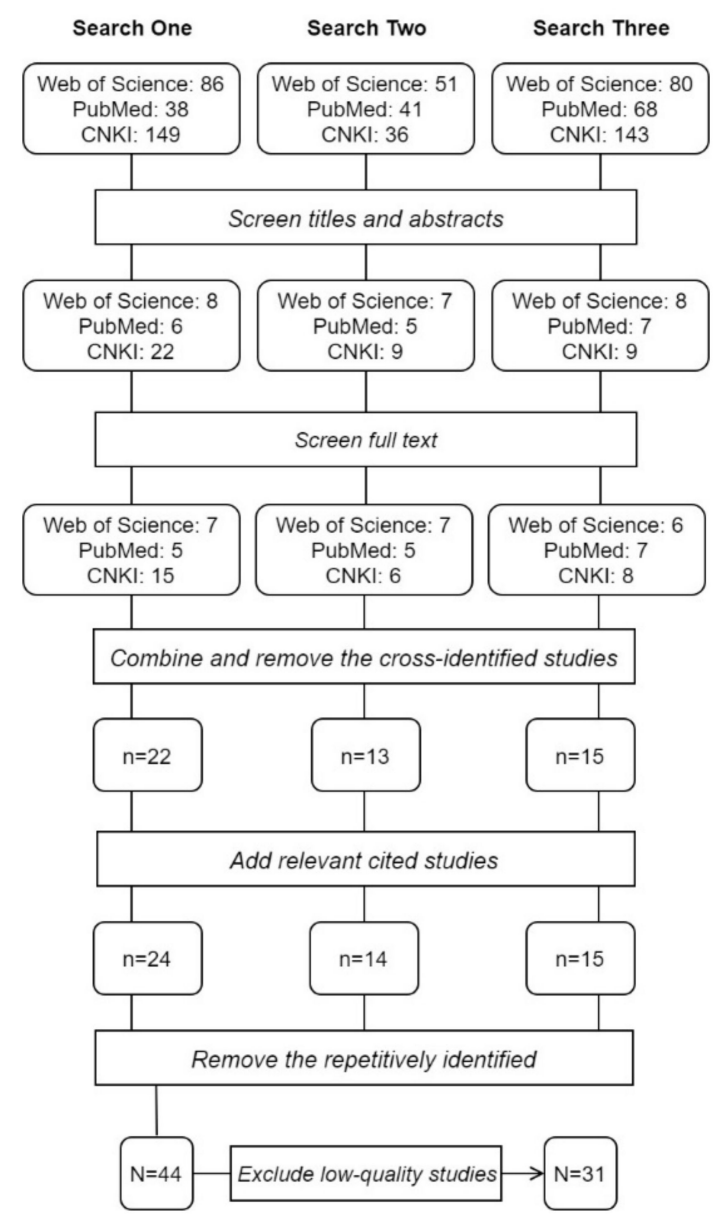

Figure 2. The flowchart of the systematic searches and selection.

Twenty-nine out of the 31 studies employed regression models as their principal methods of data analysis, adjusting for individual and aggregate background factors. Generally, these regression models included basic linear, logit, or probit models for cross-sectional data, and fixed effects, random effects, or dynamic models for longitudinal data. Some studies introduced instrumental variables to treat endogeneity. Other studies included difference-in-difference estimators to extract policy effects by comparing treatment and control groups. A few studies used the Heckman models or Two-part models to handle sample selection.

\subsection{Coverage Prevalence}

\subsubsection{Trend and Distribution}

As there is no official data about the population coverage rates of PHI from the China Insurance Regulatory Commission or other state regulatory or statistical agencies, all such estimates were derived from surveys. Studies examining nationwide representative samples (those include multiple provinces and both urban and rural areas) reported the lowest coverage rate of $4 \%$ between 2004 and 2006 and the highest coverage rate at $12 \%$ recorded in 2013 [32,40-42]. This suggests that PHI coverage prevalence gradually increased over time. Those that focused on the latest urban samples reported the highest coverage rates: $19 \%$ [43] and 35\% [44], respectively, from two studies using relatively small urban samples. Instead of population coverage, the China Insurance Regulatory Commission publishes 
Insurers' aggregate premium income of selling PHI policies (equal to customers' spending on buying PHI aside of taxes) at the provincial level every year, and all related studies in this review used the statistics. The total PHI premium income substantially increased by $1629 \%$ around the same time period, from $¥ 6.5$ ( $\approx$ US\$0.9) billion in 2000 to $¥ 112.4$ ( $\approx$ US\$15.7) billion in 2013 [45].

In terms of the distribution (Table 2), one study examined the 2006 CHNS data and found that rural residents in eastern provinces were more likely to have PHI than their inland counterparts, other things being equal [46]. Another study found that eastern provinces were associated with greater income from PHI premiums per capita than central or western inland provinces, other things being equal [47]. Two nationwide studies found that urban residents were more likely to be covered by PHI than rural residents, other things being equal $[41,48]$. Another multi-province study found that students living in urban areas were more likely to have PHI than non-students, but this phenomenon was found to disappear in rural areas [32]. One study that focused on three eastern affluent cities of Beijing, Shanghai, and Xiamen, found no significant difference in PHI coverage between urban and rural residents [44]. Additionally, one study showed that individuals who migrated from rural areas to urban areas were either more likely to be insured by PHI or completely uninsured than urban locals, other things being equal [41].

Table 2. Comparison of PHI coverage spatially or between different migration status ${ }^{1}$.

\begin{tabular}{|c|c|c|c|}
\hline Ref. ID & Study period & Comparison & Results \\
\hline [47] & $2007-2013$ & \multirow{2}{*}{ East vs. inland } & East provinces were associated with higher PHI premium income \\
\hline [46] & 2006 & & $\begin{array}{l}\text { For rural residents, living in the east was associated with a higher } \\
\text { chance of enrolment into PHI }\end{array}$ \\
\hline [48] & 2011 & \multirow{4}{*}{ Urban vs. rural } & $\begin{array}{c}\text { Living in urban areas was associated with a higher chance of enrolment } \\
\text { into PHI }\end{array}$ \\
\hline [41] & 2011,2013 & & $\begin{array}{c}\text { Living in urban areas was associated with a higher chance of enrolment } \\
\text { into PHI }\end{array}$ \\
\hline [44] & 2011 & & $\begin{array}{c}\text { Living in urban areas was NOT significantly associated with a higher } \\
\text { chance of enrolment into PHI }\end{array}$ \\
\hline [32] & 2000, 2004, 2006 & & $\begin{array}{c}\text { For students, living in urban areas was associated with a higher chance } \\
\text { of enrolment into PHI }\end{array}$ \\
\hline$[41]$ & 2011, 2013 & Migrants vs. locals & $\begin{array}{c}\text { Rural-to-urban migrants was associated with a higher chance of } \\
\text { enrolment into PHI }\end{array}$ \\
\hline
\end{tabular}

\subsubsection{Relationship between PHI and SHI Coverage}

There is mixed evidence with regards to the impact of SHI enrolment on obtaining PHI. Two studies supported a positive correlation between PHI enrolment and SHI enrolment [32,46]. However, two studies found a negative correlation [41,42], and one study reported a neutral (insignificant) relationship [40] (Table 3). Additionally, one study found that the NCMS (rural SHI scheme) membership increased adults' PHI enrolment, but decreased enrolment among children, particularly among lower income groups [14]. Another study found that enrolment in the SHI schemes (UEBMI, URBMI, and NCMS) was negatively associated with enrolment in PHI in the whole population. However, disaggregating the data suggests that the negative correlation was only significant in urban areas [41]. Another study found that enrolment in the NCMS had a negative correlation with PHI enrolment between 2004 and 2006, but the correlation became positive between 2006 and 2009 [49]. 
Table 3. Relationship between PHI prevalence and social health insurance(SHI) system expansion ${ }^{1}$.

\begin{tabular}{|c|c|c|c|c|c|c|}
\hline Ref. ID & Study Period & PHI Indicator & SHI Indicator & SHI Schemes ${ }^{2}$ & Sample & Correlation \\
\hline & \multicolumn{6}{|c|}{ Aggregate Level Evidence } \\
\hline [47] & $2007-2013$ & Income & Percentage of enrolees & All & Mixed & Positive \\
\hline [50] & 2002-2007 & Income & Percentage of enrolees & All & Mixed & Positive \\
\hline [51] & $2000-2007$ & Income & Fund income & UEBMI \& URBMI & Mixed & Positive \\
\hline [52] & 2002-2009 & Income & Fund income & UEBMI & Mixed & Positive \\
\hline [53] & 2003-2012 & Income & Average compensation & UEBMI \& URBMI & Mixed & Positive \\
\hline [54] & 2005-2010 & Income & Fund income & All & Mixed & Positive \\
\hline \multirow[t]{2}{*}{ [55] } & 2005-2011 & Compound index ${ }^{3}$ & Compound index ${ }^{4}$ & NCMS & Mixed & Positive \\
\hline & \multicolumn{6}{|c|}{ Individual Level Evidence } \\
\hline [32] & $2000,2004,2006$ & Enrolment & Enrolment & Urban schemes & Urban & Positive \\
\hline [46] & 2006 & Enrolment & Enrolment & NCMS & Rural & Positive \\
\hline \multirow[t]{2}{*}{ [42] } & 1989-2009 & Enrolment & Enrolment & All & Mixed & Negative \\
\hline & & & & & Mixed & Negative \\
\hline \multirow[t]{2}{*}[41]{} & 2011, 2013 & Enrolment & Enrolment & All & Urban & Negative \\
\hline & & & & & Rural & Neutral \\
\hline [40] & 2004-2011 & Enrolment & Enrolment & URBMI & Urban & Neutral \\
\hline [14] & 2011 & Enrolment & Enrolment & NCMS & $\begin{array}{l}\text { Adult } \\
\text { Child }\end{array}$ & $\begin{array}{l}\text { Positive } \\
\text { Negative }\end{array}$ \\
\hline [49] & 2004, 2006, 2009 & Enrolment & Enrolment & NCMS & Rural & $\begin{array}{l}\text { Negative } \\
\text { Positive }\end{array}$ \\
\hline
\end{tabular}

${ }^{1}$ If unspecified, all presented positive or negative correlations passed the significance test, otherwise neutral correlation was reported. ${ }^{2}$ UEBMI = Urban Employees' Basic Medical Insurance; URBMI = Urban Residents' Basic Medical Insurance; NCMS = New Cooperative Medical Scheme. ${ }^{3}$ Index generated by income, expenditure, claim ratio, etc. ${ }^{4}$ Index generated by income, expenditure, ratio of income and expenditure, etc.

On the contrary, all studies that examined the provincial-level correlation of insurers' income from PHI premium with SHI scheme coverage indicators concluded that SHI expansion increased insurers' income from PHI premium, other things being equal [47,50-55]. These studies examined a range of different regions, time periods, and SHI schemes. Five made regression models that controlled for demographic factors (e.g., average age, gender ratios, affluence, and education levels) [47,50-53], and two used other methods $[54,55]$.

\subsection{Access to Healthcare Services}

The findings of this review on access to healthcare were mainly informed by utilisation of healthcare services. For generic utilisation (including utilisation of both outpatient and inpatient care), the evidence is mixed. One study found that having PHI had no impact on utilisation compared with people without PHI coverage [56]. Another study found that having PHI increased utilisation compared with those without PHI for urban population but not for rural population, other things being equal [57]. The third study found that having PHI increased utilisation compared with those covered under the NCMS, other things being equal [58] (Table 4).

There is some evidence to suggest that having PHI enabled beneficiaries to utilise inpatient services, other things being equal (Table 4). Specifically, one study found that enrolment in PHI was positively associated with the utilisation of inpatient care [59]. Another study found that enrolment in PHI was associated with increasing lengths of hospitalisation between 2000 and 2004, but the association was not significant between 2006 and 2009 [60]. However, a study that focused on rural-to-urban migrants found no significant association of PHI enrolment with the migrants' inpatient utilisation [61]. At the aggregate level the findings show no significant relationship between PHI coverage prevalence and the average utilisation of inpatient services [62,63], suggesting that PHI minimally benefit inpatient utilisation for the population as a whole.

By contrast, there is minimal evidence that suggests PHI enrolment increased the utilisation of outpatient services, other things being equal (Table 4). Only one study reported a positive relationship between enrolment in PHI and outpatient utilisation [64]. However, in this study, the PHI was restricted to substitutive health insurance (enrolled in PHI only). There was no significant correlation on the effect of having complementary PHI (the marginal effect of PHI enrolment for those enrolled in both $\mathrm{PHI}$ and SHI) on utilising outpatient services. In addition, the single aggregate-level study reported 
that the percentage of PHI enrolees had a positive relationship with the average number of outpatient visits of rural counties [63].

Although few PHI policies in China cover preventative care (i.e., physical examinations and vaccinations) [65], three studies found that PHI enrolment had a significant positive relationship with the utilisation of preventative services $[60,61,66]$.

Table 4. The correlation between PHI and access to healthcare ${ }^{1}$.

\begin{tabular}{|c|c|c|c|c|c|}
\hline Ref. ID & Study Period & PHI Indicator & Type of Healthcare Utilised & Sample & Correlation \\
\hline [56] & 2004 & Enrolment & Generic healthcare & Mixed & Neutral \\
\hline [58] & 2008 & Enrolment & Generic healthcare & Mixed & Positive $^{2}$ \\
\hline [57] & 2008 & Enrolment & Generic healthcare & Mixed/urban/rural & Positive/Neutral ${ }^{3}$ \\
\hline [60] & 2000,2004 & Enrolment & $\begin{array}{l}\text { Inpatient care } \\
\text { Preventative care }\end{array}$ & Mixed & $\begin{array}{l}\text { Positive }^{4} \\
\text { Positive }\end{array}$ \\
\hline [59] & 2007,2008 & Enrolment & $\begin{array}{l}\text { Inpatient care } \\
\text { Outpatient care }\end{array}$ & Urban & $\begin{array}{l}\text { Positive } \\
\text { Neutral }\end{array}$ \\
\hline [61] & 2007-2010 & Enrolment & $\begin{array}{l}\text { Inpatient care } \\
\text { Outpatient care } \\
\text { Preventative care }\end{array}$ & $\begin{array}{l}\text { Rural-to-urban } \\
\text { migrants }\end{array}$ & $\begin{array}{l}\text { Neutral } \\
\text { Neutral } \\
\text { Positive }\end{array}$ \\
\hline [66] & 2004, 2006, 2009 & Enrolment & $\begin{array}{l}\text { Outpatient care } \\
\text { Preventative care }\end{array}$ & Rural & $\begin{array}{l}\text { Negative } \\
\text { Positive }\end{array}$ \\
\hline [64] & 2011,2013 & Enrolment & Outpatient care & Mixed & Positive/Neutral $^{5}$ \\
\hline [62] & 2006-2010 & $\begin{array}{l}\text { Provincial PHI premium } \\
\text { income over GDP }\end{array}$ & $\begin{array}{l}\text { Inpatient care (the average length of } \\
\text { hospitalisation) }\end{array}$ & Mixed & Neutral \\
\hline [63] & 2003 & $\begin{array}{l}\text { Percentage of PHI } \\
\text { enrolees in a county }\end{array}$ & $\begin{array}{l}\text { Inpatient care (the number of admissions } \\
\text { per } 1000 \text { in } 52 \text { weeks) } \\
\text { Outpatient care (the number of visits per } \\
1000 \text { in } 2 \text { weeks) }\end{array}$ & Rural & $\begin{array}{l}\text { Neutral } \\
\text { Positive }\end{array}$ \\
\hline
\end{tabular}

\footnotetext{
${ }^{1}$ If unspecified, all comparisons are between enrolees and non-enrolees of PHI, and all presented positive or negative correlations passed the significance test, otherwise neutral correlation was reported. ${ }^{2}$ Referring to the NCMS (New Cooperative Medical Scheme). ${ }^{3}$ For the whole and the urban population, not for the rural population. 4 The positive relationship exists between 2000 and 2004 but disappears between 2006 and 2009. ${ }^{5}$ Positive for PHI as primary health insurance only; no correlation for complementary PHI.
}

\subsection{Financial Protection}

The findings of this review suggest that having PHI did not reduce out of pocket payments. Two studies found that enrolment in a PHI plan was not associated with reduced out-of-pocket payments (Table 5) [56,67]. One study found that PHI increased the out-of-pocket share of total health expenditure among high-income populations but had no such effect among low-income populations between 2000 and 2004 [60]. The other study found that enrolment into PHI was associated with higher chances of out-of-pocket payments of more than $¥ 1000$ ( $\approx$ US $\$ 140$ ), and more than $¥ 5000$ ( $\approx$ US $\$ 700$ ), compared to out-of-pocket payments of less than $¥ 1000$ [44]. Only one study found that PHI reduced out-of-pocket payments for those covered solely by PHI but did not reduce out-of-pocket payment for those covered by both PHI and SHI [67].

While out-of-pocket healthcare expenditure indicates financial risk, total healthcare expenditure, measured by gross healthcare payments before insurance reimbursement, reflects the financial burden of the health system more than it indicates individuals' financial risk [44,68]. Four studies found that enrolment in PHI increased total healthcare expenditure of the enrolees (Table 5) $[42,44,57,69]$. No individual-level opposite evidence exists. Only two studies looked at the financial impacts of PHI at the aggregate data. One found that the percentage of PHI coverage had no significant impact on the per-capita annual medical expenditure at the county level [63]. The other found that per-capita PHI premium spending significantly associated with less per-capita medical expenditure at the provincial level [70]. 
Table 5. The correlation between PHI and financial risk ${ }^{1}$.

\begin{tabular}{|c|c|c|c|c|c|}
\hline Ref. ID & Study Period & PHI Indicator & Financial Risk Indicator & Sample & Correlation \\
\hline [56] & 2004 & Enrolment & Out-of-pocket payments & Mixed & Neutral \\
\hline [67] & 2011-2012 & Enrolment & Out-of-pocket payments & Mixed & Neutral/Negative ${ }^{2}$ \\
\hline [60] & 2000,2004 & Enrolment & $\begin{array}{l}\text { Out-of-pocket payments (as a share of total } \\
\text { health expenditure) }\end{array}$ & Mixed & Positive/Neutral ${ }^{3}$ \\
\hline [44] & 2011 & Enrolment & $\begin{array}{l}\text { Out-of-pocket payments exceeding } ¥ 1000 \\
\text { and } ¥ 5000 \\
\text { Total health expenditure exceeding } ¥ 1000\end{array}$ & Urban & $\begin{array}{l}\text { Positive for both } \\
\text { Positive }\end{array}$ \\
\hline [69] & 2003,2005 & Enrolment & Total health expenditure & Urban & Positive 4 \\
\hline$[57]$ & 2008 & Enrolment & Total health expenditure & Mixed/urban/rural & Positive/Neutral ${ }^{5}$ \\
\hline [42] & 1989-2009 & Enrolment & Total health expenditure & Mixed & Positive \\
\hline [63] & 2003 & $\begin{array}{l}\text { Percentage of PHI } \\
\text { enrolees in a county }\end{array}$ & Per-capita health expenditure & Rural & Neutral \\
\hline [70] & 2006-2012 & $\begin{array}{l}\text { Provincial per-capita } \\
\text { PHI premium income }\end{array}$ & Per-capita health expenditure & Mixed & Negative \\
\hline
\end{tabular}

${ }^{1}$ If unspecified, all comparisons are between enrolees and non-enrolees of $\mathrm{PHI}$, and all presented positive or negative correlations passed the significance test, otherwise neutral correlation was reported. ${ }^{2}$ Neutral for all PHI and complementary PHI, and negative for PHI as primary health insurance only. ${ }^{3}$ Only positive for the high-income group between 2000 and 2004, but neutral for the low-income group and all groups between 2006 and 2009. ${ }^{4}$ Comparing to SHI. ${ }^{5}$ Positive for the whole and the rural population, but neutral for the urban population.

\section{Discussion}

In the past 20 years, the publicly managed SHI helped China move towards expanding health insurance coverage to its population. However, the extent to which the depth (services) and height (costs) of coverage was still limited due to restricted government's financial capacity $[4,6]$, which is also an international problem for many countries on the way to approach UHC [28,29]. For policy makers, the main goal of introducing PHI was to further assist with the expansion of SHI and extend the depth and height of coverage [13,27].

This systematic review found that the coverage prevalence of PHI gradually increased since 2000, while commercial insurers' income from PHI increased to a greater extent [45]. This suggests a rapid increase in the cost of PHI and an upmarket movement of China's PHI market. Additionally, in China's PHI market, many PHI plans are sold as part of a bundle package including other savings products or life and accident insurance products [71], so it is possible that insurers' income from the whole product bundle is counted as income from PHI premium, pushing up its costs. As a result, the increase of insurers' income from PHI premium did not go along with a substantially larger number of people covered by PHI.

It is still unclear whether the expanding SHI coverage boosted or suppressed the coverage prevalence of PHI. The direct evidence about the impact of SHI enrolment on the uptake of PHI is mixed. On the contrary, there is strong evidence that the SHI expansion was associated with insurer's income increase from PHI premium, controlling for economic growth and relevant population characteristics, but the evidence is indirect since insurer's income increase from PHI premium does not equal the increase in population coverage of PHI as stated above.

One theory suggests that public health insurance programmes can crowd out PHI due to the duplication of benefits [72,73]. By contrast, several scholars have argued that public health insurance expansion may help boost the coverage prevalence of PHI. According to [15], the limited coverage of $\mathrm{SHI}$ in China can cause PHI insurers to lower their cost and introduce additional plans to attract the uninsured to purchase coverage. Meanwhile, the introduction of SHI helps disseminate knowledge about health insurance in countries where awareness of insurance is rare, increasing the demand for PHI $[13,14]$. As a result, $\mathrm{SHI}$ could theoretically cause the premium income of PHI to increase. It is, however, unclear the extent of this effect on the coverage prevalence of PHI in the Chinese context, and this needs further investigation. The review found two studies suggesting a positive correlation between having PHI and the utilisation of inpatient care while one study on rural-to-urban migrants found the correlation being neutral (Table 4). However, little evidence suggests having PHI affect the use of outpatient care. This is supported by findings from studies in other countries [74-76]. In China, the benefits package of PHI given to beneficiaries usually includes protection for critical diseases, compensation for hospitalisation, and access to superior amenities, such as VIP (premium wards, better 
services, etc.) [65,71]. However, due to price control and actuarial difficulties, most PHI plans limitedly provide coverage for outpatient services and medications $[77,78]$. This study also found a positive correlation between PHI enrolment and the utilisation of preventative services, even if few PHI plans tend to include them [65]. A possible explanation for this is that commercial insurers offer additional benefits for individuals that take advantage of using preventative services.

There is no evidence that suggests PHI can reduce out of pocket expenses for beneficiaries. PHI plans include various levels of deductibles and benefit packages. For example, many PHI policies compensate costs of hospitalisation but restrict covering medication costs. However, several studies have found that the majority of out of pocket expenses is attributable to medication costs $[77,79,80]$. Therefore, financial protection of PHI was compromised. There have been findings from Brazil and South Korea that also suggest that enrolment into PHI did not reduce out of pocket expenses on healthcare $[81,82]$.

There is evidence that PHI increased individual total health expenditure. This could cause more financial burden to governments, as a part of the expenditure must be reimbursed by insurers and insurers often receive governments subsidies for PHI. For the reasons of raising total health expenditure, in addition to utilisation increased by PHI, commercial insurers may have less bargaining power over the price of care than public insurers, particularly in a single-payer system such as the SHI system in China [20], further pushing up total health expenditure. There has been supporting evidence from foreign countries $[22,83]$.

In order to improve PHI's depth of coverage and providing financial protection, the government may want to define the mandated benefits package. For example, the governments of the Netherlands, South Africa, and to an extent, the United States, have required PHI policies to provide basic services to all their beneficiaries [84-86]. However, on one hand, effectively determining what type of covered benefits included in PHI policies needs careful consideration, and to an extent exceed the capacity of regulations. On the other hand, such policy lends itself to subsidisation. Whether it is worth subsidising PHI rather than expanding investment in SHI is open to question [87].

There was moderate evidence that suggests the distribution of PHI in China was unequal and favoured the relatively affluent urban and eastern areas. Taking into account the well-documented pro-rich demand for PHI at the individual level together [21-23], our findings thus suggest that PHI is not an effective form of coverage for low-income populations, especially for those living in less affluent areas, where there might be fewer PHI selling agencies, lower availability of PHI information, and poorer connection between insurers and healthcare providers, since PHI sellers tend to cluster in densely populated affluent urban areas for a prudent strategy [75].

Consequently, a big challenge to implementing PHI as a means for improving UHC is expanding its coverage prevalence and meanwhile protecting equity. As profitability of the PHI market in China is still questionable [13], commercial insurers hesitate to expand business to attract less affluent population groups [65]. Government subsidisation or tax break may help its expansion. However, the benefits mainly flow to the more affluent groups, as they are more likely to have the financial means to purchase PHI. In addition, affluent regions in China may introduce additional subsidies to its residents compared to less affluent regions, thus increasing inequalities with regards to accessing PHI across the country. Scholars have suggested strong government regulations against voluntary enrolment and risk-pricing of PHI to promote equal access to PHI [23]. For example, in countries like Uruguay and Switzerland, the governments mandate the purchase of PHI [87], and in the Netherlands and Chile, pricing of some PHI policies is income-related rather than risk-related [84,87].

This study has two suggestions for future research based on the findings. First, given the inconsistency between aggregate PHI premium income and coverage prevalence, to examine the coverage contribution of PHI, only analysing premium income data is at the risk of being misleading. Nevertheless, most policy articles concerning the present development and prospect of PHI in China only used premium income data $[12,13,88,89]$ possibly because it is relatively available and easy to use 
(there is insofar no official PHI take-up or population coverage data in China, except those derived from the surveys as previously mentioned).

Second, PHI plans, as voluntary for-profit health insurance schemes, are intrinsically different from SHI schemes, as SHI's objectives are set at the system level and prioritize people's health needs [25]. The nature of PHI, including enrolment that is based on capacity to pay, risk pricing, and limited population coverage, raises the concern that it could undermine the essential equity objective of UHC when it benefits the enrolees at the expense of others through relocating limited health resources according to membership rather than need $[20,25]$. However, this review found that the aggregate-level evidence that addresses health equity questions is limited and tends to be inconsistent with those from the individual level. More studies at the aggregate level is needed.

This review has several limitations. There were only a limited number of studies identified in this topic and the data used is fragmented. Therefore, it was not possible to extract the data and aggregate them to conduct a meta-analysis or any quantitative analysis. Instead, this study aimed to collate the studies on this topic and present them in a narrative way, in order to better understand how PHI has been working from the perspectives of addressing the UHC objectives in China. Second, most of the reviewed studies relied on regression models on survey data. There was a lack of experimental studies. Although many of these studies suggested causality in discussion, the results, which are basically associational, need to be interpreted with caution. Third, all the studies used quantitative data with different methodologies and data sources. This review differentiated them mainly according to validity and reliability of methods and data used, and subsequently only reviewed medium- and high-quality studies. It is impossible to rule out useful information in the low-quality group. Lastly, this review included limited studies that present the current situation in China. However, it is able to reflect on PHI's contribution to the healthcare system in place, because the basic modality of China's healthcare financing, as mentioned in the introduction, has not changed since the late 1990s [3,13], and hence, data in the 2000s-2010s remain relevant to the current situation.

\section{Conclusions}

To our knowledge, this is the first systematic literature review that focused on understanding the Chinese government's decision to expand the role of PHI to pursue UHC objectives. This review found that PHI coverage prevalence has increased moderately in China. However, the growth of PHI premium income was higher compared to take-up of the coverage type. The distribution of PHI enrolees favoured people residing in relatively affluent eastern and urban areas. Whether the expanding SHI coverage boosted or suppressed the coverage prevalence of $\mathrm{PHI}$ is still unclear. The contribution of PHI to depth of coverage was limited. Evidence suggests that it had little impact on the use of outpatient care and a mixed impact on the use of inpatient care. Coverage of PHI did not demonstrate financial protection, because it increased total health expenditure but did not reduce out-of-pocket health expenditure. In sum, it suggests that PHI's contribution to extending UHC in China has been limited and therefore should not be overstated. Government subsidisation, mandated benefits packages, and strong regulations on the PHI market may help PHI to play a more effective role in the progress towards UHC.

Supplementary Materials: The following are available online at http://www.mdpi.com/1660-4601/17/6/2049/s1, Table S1: PRISMA checklist

Author Contributions: All authors have read and agree to the published version of the manuscript. Conceptualisation, R.W.; Data curation, R.W.; Formal analysis, R.W. and N.L.; Methodology, R.W. and N.L.; Supervision, N.L.; Project administration, R.W., N.L. and A.E.; Validation, R.W. and N.L.; Visualisation, R.W., N.L. and A.E.; Roles/writing-original draft, R.W.; Writing-review \& editing, R.W., N.L. and A.E.

Funding: This work is supported by the China Scholarship Council/University of Edinburgh Joint Scholarship.

Acknowledgments: We are grateful to Mark Hellowell at the University of Edinburgh for his advice and suggestions at the early stage of the work.

Conflicts of Interest: The authors declare no conflict of interest. 


\section{Appendix A}

The Quality Assessment Protocol

After screening against the inclusion and exclusion criteria, the quality of the included papers was assessed with a quality-grading system, following the guidelines of a systematic review [38,39], and adapted from the protocols in the previous relevant studies [34-37]. In principle, it complies with the commonly adopted hierarchy of evidence in health research, i.e., systematic reviews/meta-analyses coming with the highest credibility, followed by randomised controlled trials (RCTs), cohort studies, case-control studies, cross-sectional studies, and case studies [90].

This quality-grading system gives a maximum of 10 points to an included study. While there is no review study, RCTs or case-control studies included, the grading system basically gives more points to included studies using data with longer time spans, and those methodologically controlling sample differences better and ensuring robustness of results more effectively. For the external validity, the grading system gives more points to those examining wider populations. Finally, given that many included studies focused on SHI but examined PHI in passing, the grading system gives more points to evidence from those that focused on PHI. The quality-grading system is listed at the end.

Using the quality-grading checklist, two reviewers ( $\mathrm{Wu} \mathrm{R}$ and $\mathrm{Li} \mathrm{N}$ ) independently assessed the quality of the 44 included studies, and the appraisal results from the two reviewers were compared. If the difference in the appraisal has no more than 1 point, then the average point was taken. The two reviewers discussed studies that had more than 1-point difference to reach consensus. Studies which received lower than 4 points, 4-6 points, and higher than 6 points were categorised as low, medium, or high quality, respectively.

Quality-grading checklist (total: 10 points)

1. Does this study focus on PHI? (1 point)

2. Does the study provide clear information of the used data, including source, sample size, time period, levels etc.? (1 point)

3. Are data analysed in the study nationwide sampling (including at least 15 provinces)? (2 points)

(a) Including data from at least 15 provinces (2 points);

(b) Including data from more than one province but less than 15 provinces (1 point);

(c) Data from only one province (0 point).

4. Are data analysed in the study longitudinal? (1 point)

5. How does this study deal with selection of enrolment into insurance? ( 3 points)

(a) Quasi-randomised controlled trials that create a matched control group through either a propensity score matching method or a regression discontinuity design (3 points);

(b) Difference-in-difference studies where the pre- and postintervention periods for study and control groups are the same and the characteristics of the two groups are controlled for through regression (3 points);

(c) Regression studies that consider selection through the instrumental variable method (2 points);

(d) Regression studies that control for related background variables but do not consider enrolment selection (1 point)

(e) Others (0 point)

6. Does the study examine data by applying a stratification approach? (1 point)

7. Does the study describe significance test, model robustness test, or other internal validity tests for its statistical analysis? (1 point) 


\section{Appendix B}

Table A1. Characteristics of included studies and quality assessment results.

\begin{tabular}{|c|c|c|c|c|c|c|c|c|c|c|c|c|c|c|c|c|}
\hline \multirow{2}{*}{ No. } & \multirow{2}{*}{ Studies } & \multirow{2}{*}{ Data Source } & \multirow{2}{*}{$\begin{array}{l}\text { Study } \\
\text { Period }\end{array}$} & \multirow{2}{*}{$\begin{array}{l}\text { Geographic } \\
\text { Area }\end{array}$} & \multirow{2}{*}{ Principal Method } & \multirow{2}{*}{ Reviewer * } & \multicolumn{7}{|c|}{ Quality-grading Items ${ }^{\dagger}$} & \multirow{2}{*}{$\begin{array}{l}\text { Average } \\
\text { Grade }\end{array}$} & \multirow{2}{*}{$\begin{array}{c}\text { Quality } \\
\text { Category } \ddagger\end{array}$} & \multirow[b]{2}{*}{ Action } \\
\hline & & & & & & & 1 & 2 & 3 & 4 & 5 & 6 & 7 & & & \\
\hline \multirow{2}{*}{1} & \multirow{2}{*}{ [14] } & \multirow{2}{*}{ CHNS } & \multirow{2}{*}{$\begin{array}{l}\text { 2000, } \\
2004,2006\end{array}$} & \multirow{2}{*}{9 provinces } & \multirow{2}{*}{$\begin{array}{l}\text { Logistic models with difference in difference } \\
\text { estimator, without propensity score matching }\end{array}$} & R1 & 1 & 1 & 1 & 1 & 3 & 0 & 1 & \multirow{2}{*}{8.5} & \multirow{2}{*}{ High } & \multirow{2}{*}{ Review } \\
\hline & & & & & & R2 & 1 & 1 & 1 & 1 & 3 & 1 & 1 & & & \\
\hline \multirow{2}{*}{2} & \multirow{2}{*}{ [91] } & \multirow{2}{*}{$\begin{array}{l}\text { Multi-centre retrospective } \\
\text { study with } 681 \text { patients }\end{array}$} & \multirow{2}{*}{ 2010-2013 } & \multirow{2}{*}{ Shanghai } & \multirow{2}{*}{$\begin{array}{l}\text { Chi-square tests that compare PHI enrolment } \\
\text { among different SHI status }\end{array}$} & R1 & 0 & 1 & 0 & 0 & 0 & 0 & 0 & & & \\
\hline & & & & & & R2 & 1 & 1 & 0 & 0 & 0 & 0 & 0 & 1.5 & Low & Exclude \\
\hline & & Phone survey using randomly & & & & R1 & 0 & 1 & 0 & 0 & 1 & 0 & 0 & & & \\
\hline 3 & [92] & $\begin{array}{l}\text { generated landline numbers } \\
\text { including } 1500 \text { respondents }\end{array}$ & 2010 & Shenzhen & Multivariate logistic models & R2 & 0 & 1 & 0 & 0 & 1 & 0 & 0 & 2 & Low & Exclude \\
\hline & & Phone survey using random & & Beijing, & & R1 & 1 & 1 & 1 & 1 & 1 & 1 & 0 & & & \\
\hline 4 & [44] & $\begin{array}{l}\text { digit dialling method sampling } \\
\text { landline numbers including } \\
5097 \text { households }\end{array}$ & 2011 & $\begin{array}{l}\text { Shanghai, and } \\
\text { Xiamen }\end{array}$ & Logistic models & R2 & 1 & 1 & 1 & 1 & 1 & 1 & 1 & 6.5 & High & Review \\
\hline 5 & {$[48]$} & CHARLS & 2011 & 28 provinces & Bivariate probit models for both PHI enrolment & R1 & 1 & 1 & 2 & 0 & 1 & 0 & 0 & 5 & & Review \\
\hline & & & & 28 provinces & and pension scheme enrolment & R2 & 1 & 1 & 2 & 0 & 1 & 0 & 0 & 5 & Medium & Review \\
\hline 6 & [41] & CHARLS & 2011.2013 & 28 provinces & Multinomial logistic models for five & R1 & 1 & 1 & 2 & 1 & 1 & 0 & 1 & 75 & Hioh & Review \\
\hline 6 & {$[41]$} & CHAKLS & 2011,2013 & 28 provinces & insurance status & R2 & 1 & 1 & 2 & 1 & 1 & 1 & 1 & & High & Review \\
\hline 7 & {$[40]$} & CHNS & 2004-2011 & 9 provinces & Logistic models with difference in difference & R1 & 1 & 1 & 1 & 1 & 3 & 0 & 0 & 7 & High & Review \\
\hline 7 & {$[40]$} & CHNS & 2004-2011 & 9 provinces & estimator, without propensity score matching & R2 & 1 & 1 & 1 & 1 & 3 & 0 & 0 & 7 & High & Review \\
\hline & & & & & Probit models for health services use and linear & R1 & 0 & 1 & 1 & 1 & 1 & 1 & 0 & & & \\
\hline 8 & [66] & CHNS & 2006,2009 & 9 provinces & $\begin{array}{l}\text { probability models for calculating Concentration } \\
\text { Indices }\end{array}$ & R2 & 0 & 1 & 1 & 1 & 1 & 1 & 0 & 5 & Medium & Review \\
\hline 9 & [56] & $\mathrm{CHNS}$ & 2004 & 9 provinces & Heckman selection models that select healthcare & R1 & 0 & 1 & 1 & 0 & 1 & 1 & 0 & 45 & Medium & Reviowy t \\
\hline 9 & {$[56]$} & CHNS & 2004 & 9 provinces & users and then model their OOP payments & R2 & 0 & 1 & 1 & 0 & 1 & 1 & 1 & 4.5 & Medium & Review \\
\hline & & & & & Instrumental variable regression, using the & R1 & 1 & 1 & 1 & 0 & 2 & 1 & 1 & & & \\
\hline 10 & [61] & $\begin{array}{l}\text { State Council URBMI } \\
\text { Household Survey }\end{array}$ & 2007-2010 & 9 cities & $\begin{array}{l}\text { community-year level participation rate of each } \\
\text { insurance programme among the non-migrant } \\
\text { population as the instrumental variable }\end{array}$ & R2 & 1 & 1 & 1 & 1 & 2 & 1 & 1 & 7.5 & High & Review \\
\hline & & & & & Multivariate linear models for the number of & R1 & 1 & 1 & 2 & 0 & 1 & 0 & 1 & & & \\
\hline 11 & [63] & NHSS & 2003 & 31 provinces & $\begin{array}{l}\text { outpatient visits, the number of inpatient visits } \\
\text { and per capita annual medical expenditure }\end{array}$ & R2 & 1 & 1 & 2 & 0 & 1 & 1 & 1 & 6.5 & High & Review \\
\hline & & Questionnaire survey of all first & & Pinggu district in & Chi-square tests that compare health access & R1 & 1 & 1 & 0 & 0 & 0 & 0 & 0 & & & \\
\hline 12 & [93] & $\begin{array}{l}\text { and fourth graders in four } \\
\text { elementary schools }\end{array}$ & 2005 & Beijing & indicators among different insurance status & R2 & 1 & 1 & 0 & 0 & 0 & 0 & 0 & 2 & Low & Exclude \\
\hline & & & & & Heckman selection models that selects awareness & R1 & 0 & 1 & 2 & 1 & 1 & 1 & 0 & & & \\
\hline 13 & [64] & CHARLS & 2011, 2013 & 28 provinces & $\begin{array}{l}\text { of healthcare provider ownership and model } \\
\text { utilisation for only outpatient users }\end{array}$ & R2 & 0 & 1 & 2 & 1 & 1 & 1 & 0 & 6 & Medium & Review \\
\hline & & Urban data-a hospital of PKU; & Urban- & Urban-patient in & Linear regression directly on health & R1 & 1 & 1 & 1 & 1 & 1 & 0 & 0 & & & \\
\hline 14 & [69] & $\begin{array}{l}\text { rural data-a survey in } 101 \\
\text { villages }\end{array}$ & $\begin{array}{l}2003 ; \\
\text { rural-2005 }\end{array}$ & $\begin{array}{l}\text { Beijing; rural-5 } \\
\text { provinces }\end{array}$ & expenditure data & R2 & 1 & 1 & 1 & 1 & 1 & 0 & 0 & 5 & Medium & Review \\
\hline
\end{tabular}


Table A1. Cont.

\begin{tabular}{|c|c|c|c|c|c|c|c|c|c|c|c|c|c|c|c|c|}
\hline \multirow{2}{*}{ No. } & \multirow{2}{*}{ Studies } & \multirow{2}{*}{ Data Source } & \multirow{2}{*}{$\begin{array}{l}\text { Study } \\
\text { Period }\end{array}$} & \multirow{2}{*}{$\begin{array}{l}\text { Geographic } \\
\text { Area }\end{array}$} & \multirow{2}{*}{ Principal Method } & \multirow{2}{*}{ Reviewer * } & \multicolumn{7}{|c|}{ 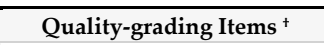 } & \multirow{2}{*}{$\begin{array}{l}\text { Average } \\
\text { Grade }\end{array}$} & \multirow{2}{*}{$\begin{array}{c}\text { Quality } \\
\text { Category }\end{array}$} & \multirow[b]{2}{*}{ Action } \\
\hline & & & & & & & 1 & 2 & 3 & 4 & 5 & 6 & 7 & & & \\
\hline \multirow[b]{2}{*}{15} & \multirow[b]{2}{*}{ [94] } & \multirow[b]{2}{*}{ NHSS } & \multirow[b]{2}{*}{2008,2013} & \multirow[b]{2}{*}{$\begin{array}{l}\text { Rural Shaanxi } \\
\text { province }\end{array}$} & \multirow{2}{*}{$\begin{array}{l}\text { Decomposition based on the logistic model for } \\
\text { the incidence of catastrophic health expenditure } \\
\text { representing OOP payments over } 40 \% \text { of the } \\
\text { household capacity to pay }\end{array}$} & R1 & 0 & 1 & 0 & 1 & 1 & 0 & 0 & \multirow[b]{2}{*}{3} & \multirow[b]{2}{*}{ Low } & \multirow[b]{2}{*}{ Exclude } \\
\hline & & & & & & R2 & 0 & 1 & 0 & 1 & 1 & 0 & 0 & & & \\
\hline \multirow{2}{*}{16} & \multirow{2}{*}{ [95] } & \multirow{2}{*}{ NHSS } & & Gansu province & Kakwani index of progressivity of healthcare & R1 & 0 & 1 & 0 & 1 & 0 & 0 & 1 & 3.5 & Low & Exclude \\
\hline & & & 2002, 2007 & Gansu province & payments on gross income & R2 & 0 & 1 & 0 & 1 & 0 & 1 & 1 & 3.5 & Low & Exclude \\
\hline & & & & Heilongjiang & Kakwani index of progressivity of healthcare & R1 & 0 & 1 & 0 & 1 & 0 & 0 & 1 & 3 & & \\
\hline 17 & [96] & NHSS & 2002,2007 & province & payments on gross income & R2 & 0 & 1 & 0 & 1 & 0 & 0 & 1 & 3 & Low & Exclude \\
\hline 18 & {$[50]$} & State statistics & 2002-2007 & 3 provinces & Linear models & R1 & 1 & 1 & 1 & 1 & 1 & 1 & 0 & 6 & Medium & Reviowy \\
\hline 18 & {$[30]$} & State statistics & $2002-2007$ & 3 provinces & Linear models & R2 & 1 & 1 & 1 & 1 & 1 & 1 & 0 & 6 & Medium & Review \\
\hline 19 & {$[55]$} & State statistics & 2005-2011 & Nationwide & Degree of coupling referring to coupling theory & R1 & 1 & 1 & 2 & 1 & 0 & 0 & 0 & 5 & Medium & Review \\
\hline & [35] & State statistics & $2000-2011$ & Nationwide & in Physics & R2 & 1 & 1 & 2 & 1 & 0 & 0 & 0 & 3 & Meaium & \\
\hline 20 & {$[52]$} & State statistics & $2002-2009$ & 30 Provinces & Dynamic panel models with a first order lag & R1 & 1 & 1 & 2 & 1 & 1 & 0 & 1 & 7 & & Review \\
\hline & & & & & & R2 & 1 & 1 & 2 & 1 & 1 & 0 & 1 & 7 & High & Review \\
\hline 21 & [51] & State statistics & $2000-2007$ & Nationwide & Linear models. & R1 & 1 & 1 & 2 & 1 & 1 & 0 & 1 & 7 & High & Review \\
\hline & & & & & & R2 & 1 & 1 & 2 & 1 & 1 & 0 & 1 & & & \\
\hline 22 & {$[54]$} & State statistics & $2005-2010$ & Nationwide & Degree of Coordination based on the composite & R1 & 1 & 1 & 2 & 1 & 0 & 1 & 0 & 6 & Medium & Review \\
\hline 22 & [34] & State statistics & 2003-2010 & Nationwide & system synergy degree model & R2 & 1 & 1 & 2 & 1 & 0 & 1 & 0 & 6 & Medium & Review \\
\hline & & & & & Logistic models for PHI enrolment, and fixed & R1 & 1 & 1 & 1 & 1 & 2 & 0 & 1 & & & \\
\hline 23 & [42] & CHNS & 1989-2009 & 9 provinces & $\begin{array}{l}\text { effect models and instrumental variable } \\
\text { regression for total health expenditure }\end{array}$ & R2 & 1 & 1 & 1 & 1 & 2 & 0 & 1 & 7 & High & Review \\
\hline 24 & [49] & CHNS & 20042006 & 9 provinces & Probit models with difference in difference & R1 & 1 & 1 & 1 & 1 & 3 & 0 & 0 & 7 & High & Review \\
\hline 24 & {$[49]$} & CHNS & 2009 & oprovinces & estimator, without propensity score matching & R2 & 1 & 1 & 1 & 1 & 3 & 0 & 0 & r & Fign & Review \\
\hline & & Household survey using & & & & R1 & 1 & 1 & 0 & 0 & 1 & 0 & 0 & & & \\
\hline 25 & [97] & $\begin{array}{l}\text { stratified sampling including } \\
1600 \text { households }\end{array}$ & 2006 & $\begin{array}{l}\text { Snangnal } \\
\text { municipality }\end{array}$ & Linear models for logged expenditure on PHI & R2 & 1 & 1 & 0 & 0 & 1 & 0 & 0 & 3 & Low & Exclude \\
\hline 26 & {$[32]$} & CHNS & 2000, & 9 provinces & Bivariate probit models with partial observability & R1 & 1 & 1 & 1 & 1 & 1 & 0 & 0 & 5.5 & Medium & Review \\
\hline 20 & {$[32]$} & CHINS & 2004, 2006 & & & R2 & 1 & 1 & 1 & 1 & 1 & 1 & 0 & & & \\
\hline 27 & [46] & CHNS & 2006 & 9 provinces & Bivariate probit models for both PHI enrolment & R1 & 1 & 1 & 1 & 0 & 1 & 1 & 0 & 5.5 & Medium & Review \\
\hline & & & & & and NCMS enrolment & R2 & 1 & 1 & 1 & 0 & 1 & 1 & 1 & 0.3 & & \\
\hline 28 & [53] & State statistics & 2003-2012 & Nationwide & Fixed effects models with per capita outpatient & R1 & 1 & 1 & 2 & 1 & 2 & 0 & 0 & 7.5 & High & Review \\
\hline & & Sale statistics & & Nationwide & expenditure as the instrumental variable & R2 & 1 & 1 & 2 & 1 & 2 & 0 & 1 & & & \\
\hline 29 & [47] & State statistics & $2007-2013$ & 31 provinces & Fixed effects models & R1 & 1 & 1 & 2 & 1 & 1 & 1 & 1 & 8 & High & Review \\
\hline & & & & & & R2 & 1 & 1 & 2 & 1 & 1 & 1 & 1 & & & \\
\hline 30 & [31] & State statistics & 2004-2013 & 31 provinces & Linear models & R1 & 1 & 1 & 2 & 1 & 1 & 1 & 0 & 7 & High & Review \\
\hline & [51] & & & & & R2 & 1 & 1 & 2 & 1 & 1 & 1 & 0 & 7 & 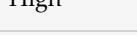 & Review \\
\hline 31 & [43] & Questionnaire survey including & 2012-2013 & 5 cities & Logistic models & R1 & 1 & 1 & 1 & 0 & 1 & 0 & 1 & 5 & Medium & Reviow \\
\hline & & 557 individuals & & & Logistic models & R2 & 1 & 1 & 1 & 0 & 1 & 0 & 1 & 0 & - viedum & Neview \\
\hline
\end{tabular}


Table A1. Cont.

\begin{tabular}{|c|c|c|c|c|c|c|c|c|c|c|c|c|c|c|c|c|}
\hline \multirow{2}{*}{ No. } & \multirow{2}{*}{ Studies } & \multirow{2}{*}{ Data Source } & \multirow{2}{*}{$\begin{array}{l}\text { Study } \\
\text { Period }\end{array}$} & \multirow{2}{*}{$\begin{array}{l}\text { Geographic } \\
\text { Area }\end{array}$} & \multirow{2}{*}{ Principal Method } & \multirow{2}{*}{ Reviewer * } & \multicolumn{7}{|c|}{ 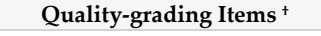 } & \multirow{2}{*}{$\begin{array}{l}\text { Average } \\
\text { Grade }\end{array}$} & \multirow{2}{*}{$\begin{array}{c}\text { Quality } \\
\text { Category }{ }^{\ddagger}\end{array}$} & \multirow{2}{*}{ Action } \\
\hline & & & & & & & 1 & 2 & 3 & 4 & 5 & 6 & 7 & & & \\
\hline \multirow[b]{2}{*}{32} & \multirow[b]{2}{*}{ [98] } & \multirow{2}{*}{$\begin{array}{l}\text { Questionnaire survey of two } \\
\text { districts. This study only } \\
\text { included } 900 \text { working } \\
\text { individuals of } 1600 \text { samples }\end{array}$} & \multirow[b]{2}{*}{2010} & \multirow[b]{2}{*}{$\begin{array}{l}\text { Tianjin } \\
\text { municipality }\end{array}$} & \multirow{2}{*}{$\begin{array}{l}\text { Heckman-probit models that select willingness to } \\
\text { buy PHI and then model the level of expenditure on } \\
\text { PHI }\end{array}$} & R1 & 1 & 1 & 0 & 0 & 1 & 0 & 0 & & & \\
\hline & & & & & & $\mathrm{R} 2$ & 1 & 1 & 0 & 0 & 1 & 0 & 1 & 3.5 & Low & Exclude \\
\hline \multirow{2}{*}{33} & \multirow{2}{*}{ [58] } & \multirow{2}{*}{ CHARLS } & \multirow{2}{*}{2008} & \multirow{2}{*}{2 provinces } & \multirow{2}{*}{$\begin{array}{l}\text { Logistic and multi-nominal models for types of } \\
\text { healthcare }\end{array}$} & R1 & 1 & 1 & 1 & 0 & 1 & 0 & 0 & 4.5 & Medium & Review \\
\hline & & & & & & $\mathrm{R} 2$ & 1 & 1 & 1 & 0 & 1 & 1 & 0 & 4.5 & Miedium & keview \\
\hline \multirow{2}{*}{34} & \multirow{2}{*}{ [99] } & \multirow{2}{*}{$\begin{array}{l}\text { Questionnaire survey of a city } \\
\text { including } 1200 \text { individuals }\end{array}$} & \multirow{2}{*}{2011} & Dongguan city & Chi-square tests that compare utilisation among & R1 & 0 & 1 & 0 & 0 & 0 & 0 & 0 & 1 & Low & Exclude \\
\hline & & & & Dongguan city & different health insurance status & $\mathrm{R} 2$ & 0 & 1 & 0 & 0 & 0 & 0 & 0 & 1 & Low & Excruade \\
\hline 35 & [57] & CHARLS & 2008 & 2 provinces & Two-part models that select utilisation at first and & R1 & 1 & 1 & 1 & 0 & 1 & 0 & 0 & 4 & & Review \\
\hline & 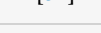 & (1) & 2000 & 2 piovintes & then model logged health expenditure & R2 & 1 & 1 & 1 & 0 & 1 & 0 & 0 & 4 & Mearum & Neview \\
\hline 36 & [62] & State statistics & 2006-2010 & Nationwide & Fixed effects models for the average length of & R1 & 1 & 1 & 2 & 1 & 1 & 0 & 0 & 6 & Medium & Review \\
\hline 36 & {$\left[{ }^{[22]}\right.$} & State statistics & $2000-2010$ & Nationwide & hospitalisation & $\mathrm{R} 2$ & 1 & 1 & 2 & 1 & 1 & 0 & 0 & 6 & Mearum & keview \\
\hline & & Household survey using & & & & R1 & 0 & 1 & 0 & 0 & 1 & 0 & 0 & & & \\
\hline 37 & [100] & $\begin{array}{l}\text { multilevel stratified sampling } \\
\text { including } 5928 \text { households }\end{array}$ & 2014 & Sichuan province & Logistics models & R2 & 0 & 1 & 0 & 0 & 1 & 0 & 0 & 2 & Low & Exclude \\
\hline & & & & & Logistic and linear models with difference in & R1 & 1 & 1 & 1 & 1 & 3 & 0 & 0 & & & \\
\hline 38 & [60] & CHNS & $\begin{array}{l}\text { 2004, } \\
\text { 2006, } 2009\end{array}$ & 9 provinces & $\begin{array}{l}\text { difference estimator, without propensity score } \\
\text { matching }\end{array}$ & R2 & 1 & 1 & 1 & 1 & 3 & 0 & 0 & 7 & High & Review \\
\hline 39 & {$[59]$} & State Council URBMI & 2007, 2008 & 9 cities & 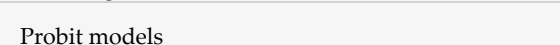 & R1 & 1 & 1 & 1 & 1 & 1 & 1 & 1 & 7 & $\mathrm{High}$ & Review \\
\hline & & Household Survey & 2000,2000 & 5crues & Itoont moders & R2 & 1 & 1 & 1 & 1 & 1 & 1 & 1 & r & ח & Review \\
\hline 40 & {$[67]$} & Chinese longitudinal Healthy & 2011-2012 & 23 provinces & Linear models & R1 & 1 & 1 & 2 & 0 & 1 & 0 & 0 & 5 & Medium & Review \\
\hline 40 & [0/] & Longevity Survey (CLHLS) & $2011-2012$ & 20 provinces & Linedr moders & R2 & 1 & 1 & 2 & 0 & 1 & 0 & 0 & & Miedium & Review \\
\hline & & & & & Chi-square tests that compare the incidence of & R1 & 0 & 1 & 1 & 0 & 0 & 0 & 0 & & & \\
\hline 41 & [101] & $\begin{array}{l}\text { Questionnaire survey including } \\
4800 \text { individuals }\end{array}$ & 2014 & 8 provinces & $\begin{array}{l}\text { catastrophic health expenditure indicated by OOP } \\
\text { payments over } 40 \% \text { of the household capacity to } \\
\text { pay between PHI enrolment status }\end{array}$ & R2 & 0 & 1 & 1 & 0 & 0 & 0 & 0 & 2 & Low & Exclude \\
\hline 42 & [102] & NHSS & 2003, 2008 & Rural Xinjiang & Kakwani index & R1 & 1 & 1 & 0 & 1 & 0 & 0 & 0 & 3 & Low & Exclude \\
\hline 42 & {$[102]$} & 1 NIIOS & 2000,2000 & province & Nakwantumex & $\mathrm{R} 2$ & 1 & 1 & 0 & 1 & 0 & 0 & 0 & & Low & Exciude \\
\hline 43 & {$[103]$} & Third Corps Survey & 2010 & Xingiiang Corps & Aronson-Iohnson-Lambert Redistributive effect & R1 & 1 & 1 & 0 & 0 & 0 & 0 & 0 & 2 & Low & Exclude \\
\hline (5) & {$[100]$} & 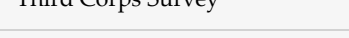 & 2010 & Aingering torps & 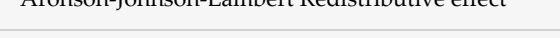 & $\mathrm{R} 2$ & 1 & 1 & 0 & 0 & 0 & 0 & 0 & 2 & Low & Excrude \\
\hline 44 & [70] & State statistics & 2006-2012 & 31 provinces & Fixed effects models & R1 & 1 & 1 & 2 & 1 & 1 & 0 & 1 & 7 & High & Review \\
\hline$x^{-}$ & (10) & (2) & 20000 & 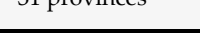 & Tixed entects induets & $\mathrm{R} 2$ & 1 & 1 & 2 & 1 & 1 & 0 & 1 & r & & \\
\hline
\end{tabular}

${ }^{*} \mathrm{R} 1=\mathrm{R} . \mathrm{Wu} ; \mathrm{R} 2=\mathrm{N}$. Li. + The item number corresponds to that in the quality-grading checklist in Appendix A. Except No. 2, that has a maximum of two points, and No. 5, that has a maximum of three points, all others have a maximum of one point. $\ddagger$ low quality (0-3.5 points), medium quality (4-6 points), and high quality (6.5-10 points) 


\section{References}

1. Health Expenditure, Public (\% of Total Health Expenditure). Available online: https://data.worldbank.org/ indicator/SH.XPD.PUBL?view=chart (accessed on 21 September 2019).

2. Dai, B.; Zhou, J.; Mei, Y.J.; Wu, B.; Mao, Z. Can the New Cooperative Medical Scheme promote rural elders' access to health-care services? Geriatr. Gerontol. Int. 2011, 11, 239-245. [CrossRef] [PubMed]

3. Liang, L.; Langenbrunner, J.C. The Long March to Universal Coverage: Lessons from China; Cotlear, D., Ed.; The World Bank: Washington, DC, USA, 2013.

4. Meng, Q.; Xu, L.; Zhang, Y.; Qian, J.; Cai, M.; Xin, Y.; Barber, S.L. Trends in access to health services and financial protection in China between 2003 and 2011: A cross-sectional study. Lancet 2012, 379, 805-814. [CrossRef]

5. Meng, Q.; Xu, L. Monitoring and evaluating progress towards Universal Health Coverage in China. PLoS Med. 2014, 11, e1001694. [CrossRef] [PubMed]

6. Yip, W.C.M.; Hsiao, W.C.; Chen, W.; Hu, S.; Ma, J.; Maynard, A. Early appraisal of China's huge and complex health-care reforms. Lancet 2012, 379, 833-842. [CrossRef]

7. National Health and Family Planning Commission. China Health Statistical Yearbook; National Health and Family Planning Commission: Beijing, China, 2013.

8. Yip, W.C.M.; Hsiao, W.C. China's health care reform: A tentative assessment. China Econ. Rev. 2009, 20, 613-619. [CrossRef]

9. Meng, Q.; Fang, H.; Liu, X.; Yuan, B.; Xu, J. Consolidating the social health insurance schemes in China: Towards an equitable and efficient health system. Lancet 2015, 386, 1484-1492. [CrossRef]

10. Ministry of Human Resource and Social Security. Summary of National Social Insurance; Ministry of Human Resource and Social Security: Beijing, China, 2012.

11. Center for Health Statistics and Information, National Health and Family Planning Commission (China). China Health and Family Planning Statistics Yearbook; Peking Union Medical College Press: Beijing, China, 2013.

12. Duan, J. Historical opportunity of commercial health insurance development in China. China Insur. 2008, 8, $14-21$.

13. Xiang, J. Developing commercial health insurance, serving China's reform on the medical and health system. Insur. Stud. 2014, 12, 3-13.

14. Liu, H.; Gao, S.; Rizzo, J.A. The expansion of public health insurance and the demand for private health insurance in rural China. China Econ. Rev. 2011, 22, 28-41. [CrossRef]

15. Barros, P.P.; Siciliani, L. Public and Private Sector Interface. In Handbook of Health Economics; Pauly, M.V., McGuire, T.G., Barros, P.P., Eds.; Elsevier: Oxford, UK, 2012; Volume 2.

16. CPCCC. State Council. In Opinions on Deepening Health Reforms Beijing; State Council of the People's Republic of China: Beijing, China, 2009.

17. Ernst \& Young. China Launches Pilot Individual Income Tax policy for Commercial Health Insurance Products; Ernst \& Young LLP: London, UK, 2016.

18. WHO. Advancing and sustaining universal coverage. In The World Health Report 2008, Primary Health Care-Now more than Ever; World Health Organization: Geneva, Switzerland, 2008.

19. Van de Ven, W.P.M.M. Making Health Insurance Affodable: Role of Risk Equalization. In Scaling Up Affordable Health Insurance; Preker, A.S., Lindner, M.E., Chernichovsky, D., Onno, P.S., Eds.; The World Bank: Washington, DC, USA, 2013.

20. Colombo, F. Lessons for Developing Countries from the OECD. In Private Voluntary Health Insurance in Development: Friend or Foe? Preker, A.S., Scheffler, R.M., Bassett, M.C., Eds.; The World Bank: Washington, DC, USA, 2007.

21. Arrow, K.J. UNCERTAINTY AND THE Welf. ECONOMICS OF MEDICAL-CARE. Am. Econ. Rev 1963, 53, 941-973.

22. Einav, L.; Finkelstein, A. Moral hazard in health insurance: What we know and how we know it. J. Eur. Econ. Assoc. 2018, 16, 957-982. [CrossRef] [PubMed]

23. Sekhri, N.; Savedoff, W. Regulating private health insurance to serve the public interest: Policy issues for developing countries. Int. J. Health Plan. Manag. 2006, 21, 357-392. [CrossRef] [PubMed] 
24. Pauly, M.V. Insights on Demand for Private Voluntary Health Insurance in Less Developed Countries. In Private Voluntary Health Insurance in Development: Friend or Foe? x; Preker, A.S., Scheffler, R.M., Bassett, M.C., Eds.; The World Bank: Washington, DC, USA, 2007; pp. 25-54.

25. Kutzin, J. Health financing for universal coverage and health system performance: Concepts and implications for policy. Bull. World Health Organ. 2013, 91, 602-611. [CrossRef] [PubMed]

26. Preker, A.S. The Evolution of Health Insurance in Developing Countries. In Private Voluntary Health Insurance in Development: Friend or Foe? Preker, A.S., Scheffler, R.M., Bassett, M.C., Eds.; The World Bank: Washington, DC, USA, 2007; pp. 1-22.

27. Gu, X. Position of Commercial Health Insurance in Universal Health Care. Comp. Econ. Soc. Syst. 2009, 6, 52-59.

28. Preker, A.S.; Lindner, M.E.; Chernichovsky, D.; Onno, P.S. Introduction: Public Options, Private Choices. In Scaling Up Affordable Health Insurance; Preker, A.S., Lindner, M.E., Chernichovsky, D., Onno, P.S., Eds.; The World Bank: Washington, DC, USA, 2013.

29. Scheil-Adlung. Health Protection: More Than Financial Protection. In Scaling Up Affordable Health Insurance; Preker, A.S., Lindner, M.E., Chernichovsky, D., Onno, P.S., Eds.; The World Bank: Washington, DC, USA, 2013.

30. WHO. World Health Report, 2010: Health Systems Financing the Path to Universal Coverage; World Health Organisation: Geneva, Switzerland, 2010.

31. Suo, L.; Wanyan, R.; Chen, T. A research on the uneven development of health insurance and its reasons. Insur. Stud. 2015, 1, 42-53.

32. Liu, H.; Wang, J. An empirical analysis of private health insurance ownership in China. China Econ. Q. 2012, 11, 1525-1548.

33. Moher, D.; Liberati, A.; Tetzlaff, J.; Altman, D.G. Preferred reporting items for systematic reviews and meta-analyses: The PRISMA statement. Ann. Intern. Med. 2009, 151, 264-269. [CrossRef]

34. Ekman, B. Community-based health insurance in low-income countries: A systematic review of the evidence. Health Policy Plan. 2004, 19, 249-270. [CrossRef]

35. Spaan, E.; Mathijssen, J.; Tromp, N.; McBain, F.; Have, A.T.; Baltussen, R. The impact of health insurance in Africa and Asia: A systematic review. Bull. World Health Organ. 2012, 90, 685-692. [CrossRef]

36. Liang, X.; Guo, H.; Jin, C.; Peng, X.; Zhang, X. The Effect of New Cooperative Medical Scheme on Health Outcomes and Alleviating Catastrophic Health Expenditure in China: A Systematic Review. Plos One 2012, 7, e40850. [CrossRef]

37. Acharya, A.; Vellakkal, S.; Taylor, F.; Masset, E.; Satija, A.; Burke, M. The Impact of Health Insurance Schemes for the Informal Sector in Low- and Middle-Income Countries: A Systematic Review. World Bank Res. Obs. 2013, 28, 236-266. [CrossRef]

38. Akers, J.; Aguiar-Ibáñez, R.; Baba-Akbari Sari, A. CRD's Guidance for Undertaking Reviews in Health Care; Centre for Reviews and Dissemination (CRD): York, UK, 2009.

39. Petticrew, M.; Roberts, H. Systematic Reviews in the Social Sciences: A Practical Guide; Blackwell Publishing Ltd.: Oxford, UK, 2006.

40. Hou, X.; Zhang, J. The effects of public health insurance expansion on private health insurance in urban China. Int. J. Health Econ. Manag. 2017, 17, 359-375. [CrossRef]

41. Jin, Y.; Hou, Z.; Zhang, D. Determinants of Health Insurance Coverage among People Aged 45 and over in China: Who Buys Public, Private and Multiple Insurance. Plos ONE 2016, 11, e0161774. [CrossRef] [PubMed]

42. Yuan, Z.; Sun, Y.; Chen, Z. Moral Hazard in the commercial medical insurance in China. Insur. Stud. 2014, 6, 53-62.

43. Dong, M.; Zhao, Y. An analysis of current determinants of buying commercial health insurance. Stat. Obs. 2013, 395, 103-106.

44. Fang, K.N.; Shia, B.C.; Ma, S.G. Health Insurance Coverage and Impact: A Survey in Three Cities in China. Plos ONE 2012, 7, e39157. [CrossRef] [PubMed]

45. China Insurance Regulatory Commission. Yearbook of China's Insurance; China Insurance Regulatory Commission: Beijing, China, 2014.

46. Qu, D.; Wang, J. An analysis of Chinese rural residents' medical insurance demand and its determinants. Insur. Stud. 2010, 4, 61-65. 
47. Wang, W.; Peng, R.; Wang, T.; Lai, X. A determinant study on the demand for private health insurance: Based on modeling panel data. Zhejiang Financ. 2015, 5, 56-60.

48. Yue, Y.; Zou, J. The Role of Wealth and Health in Insurance Choice: Bivariate Probit Analysis in China. Math. Probl. Eng. 2014, 2014, 9. [CrossRef]

49. Xu, R.; Zhang, D.; Ji, X. A research on the effects of NCMS on the rural demand for commercial medical insurance. Insur. Stud. 2013, 3, 120-127.

50. Li, Q. The influential factor analysis of premium income of commercial health insurance: A comparison between Hubei, Beijing and Shanghai. South China Financ. 2009, 7, 55-59.

51. Wang, L. The analysis of effective demand on health insurance. Technoecon. Manag. Res. 2009, 1, 100-102.

52. Wang, X. Social health insurance, market structure and China's commercial health insurance development. Insur. Stud. 2011, 7, 35-41.

53. Zhu, M.; Gui, Z. Public and private health insurance in medical expenditure financing: An analysis based on 2003-2012 China' s provincial panel data of urban areas. Insur. Stud. 2014, 6, 96-104.

54. Zheng, R.; Hua, J. The degree of coordination between commercial medical insurance and social medical insurance in China. Insur. Stud. 2013, 4, 101-109.

55. Lv, Z. A study on the collaborative development of commercial health insurance and social health insurance: Based on coupling theory. J. Shandong Univ. 2013, 6, 45-54.

56. You, X.; Kobayashi, Y. Determinants of out-of-pocket health expenditure in China: Analysis using China Health and Nutrition Survey data. Appl. Health Econ. Health Policy 2011, 9, 39-49. [CrossRef]

57. Chai, H.-M. An empirical analysis of demand for health care and medical insurance of Chinese urban and rural residents. World Econ. Pap. 2013, 5, 107-119.

58. Chai, H.-M. Study of the health care utilization and multi-health insurance schemes in China. Med. Philos. 2014, 35, 7-10.

59. Zang, W.; Zhao, S.; Liu, G. The analysis of adverse selection in China's urban basic medical insurance programs. China Econ. Q. 2012, 12, 47-70.

60. Jiao, N. A Research on the Selection of Commercial Medical Insurance and the Healthcare Needs of Residents in China: An Empirical Analysis Based on DID. J. Yunnan Financ. Trade Inst. 2015, 174, 91-99.

61. Qin, X.; Pan, J.; Liu, G.G. Does participating in health insurance benefit the migrant workers in China? An empirical investigation. China Econ. Rev. 2014, 30, 263-278. [CrossRef]

62. Wang, Q. The Study of the Effect of Health Insurance on Medical Care Quality. Res. Econ. Manag. 2012, 10, 24-31.

63. Chau, K.L. Ecological analysis of health care utilisation for China's rural population: Association with a rural county's socioeconomic characteristics. Bmc Public Health 2010, 10, 664. [CrossRef]

64. Wang, Q.; Zhang, D.L.; Hou, Z.Y. Insurance coverage and socioeconomic differences in patient choice between private and public health care providers in China. Soc. Sci. Med. 2016, 170, 124-132. [CrossRef]

65. Ernst \& Young. The Rise of Private Health Insurance in China: Consumer Demand Presents Huge Opportunities and Risks; Ernst \& Young LLP: London, UK, 2016.

66. Yang, W. China's new cooperative medical scheme and equity in access to health care: Evidence from a longitudinal household survey. Int. J. Equity Health 2013, 12, 20. [CrossRef]

67. Zeng, Y.; Ou, L.; Yang, T.; Fang, Y. The effect of medical insurance impact on Chinese elderly's medical expense: Results from the survey of CLHLS. Chin. J. Gerontol. 2017, 37, 710-713.

68. Xu, K.; Saksena, P.; Holly, A. The Determinants of Health Expenditure: A Country-Level Panel Data Analysis; World Health Organisation: Geneva, Switzerland, 2011; Volume 26.

69. Wang, H.H.; Huang, S.; Zhang, L.; Rozelle, S.; Yan, Y. A comparison of rural and urban healthcare consumption and health insurance. China Agric. Econ. Rev. 2010, 2, 212-227. [CrossRef]

70. Cui, E.; Jiang, S.; Jia, S. Research on the Impact of Environmental Pollution, Commercial Health Insurance to Health Costs: Based on the Empirical Analysis of Provincial Panel Data. Nankai Econ. Stud. 2016, 6, 140-150.

71. Ng, A.; Dyckerhoff, C.; Then, F. Private Health Insurance in China: Finding the Winning Formula; McKinsey's Healthcare Systems and Services Practice; Health International, McKinsey and Company: New York, NY, USA, 2012.

72. Cutler, D.M.; Gruber, J. Does public insurance crowd out private insurance? Q. J. Econ. 1996, 111, $391-430$. [CrossRef] 
73. Shore-Sheppard, L.; Buchmueller, T.C.; Jensen, G.A. Medicaid and crowding out of private insurance: A re-examination using firm level data. J. Health Econ. 2000, 19, 61-91. [CrossRef]

74. Nolan, B. The interaction of public and private health insurance: Ireland as a case study. Geneva Pap. Risk Insur. Issues Pract. 2006, 31, 633-649. [CrossRef]

75. Zweifel, P.; Krey, B.B.; Tagli, M. Supply of Private Voluntary Health Insurance in Low-Income Countries. In Private Voluntary Health Insurance in Development: Friend or Foe? Preker, A.S., Scheffler, R.M., Bassett, M.C., Eds.; The World Bank: Washington, DC, USA, 2007.

76. Bowie, R.; Adams, G. Financial and Management Best Practice in Private Voluntary Health Insurance. In Private Voluntary Health Insurance in Development: Friend or Foe? Preker, A.S., Scheffler, R.M., Bassett, M.C., Eds.; The World Bank: Washington, DC, USA, 2007.

77. Pauly, M.V.; Blavin, F.E.; Meghan, S. How private, voluntary health insurance can work in developing countries. Health Affairs. 2009, 28, 1778-1787. [CrossRef] [PubMed]

78. Qiu, C.; Chen, T. Risk factors of losses of commercial medical insurance: An empirical analysis using generalised linear models. Chin. J. Appl. Probab. 2012, 28, 389-399.

79. China National Health Development Research Center. China National Health Accounts Report; National Health and Family Planning Commission: Beijing, China, 2014.

80. Pauly, M.V. The evolution of health insurance in India and China. Health Affairs. 2008, 27, 1016-1019. [CrossRef]

81. Barros, A.J.; Bastos, J.L.; Dâmaso, A.H. Catastrophic spending on health care in Brazil: Private health insurance does not seem to be the solution. Cad. Saude Publica 2011, 27, s254-s262. [CrossRef]

82. Shin, J. Private health insurance in South Korea: An international comparison. Health Policy 2012, 108, 76-85. [CrossRef]

83. Colombo, F.; Tapay, N. Private Health Insurance in OECD Countries; OECD: Paris, France, 2004.

84. Enthoven, A.C.; van de Ven, W.P.M.M. Going Dutch-Managed-competition health insurance in the Netherlands. N. Engl. J. Med. 2007, 357, 2421-2423. [CrossRef]

85. Mills, A.; Ataguba, J.E.; Akazili, J.; Borghi, J.; Garshong, B.; Makawia, S.; McIntyre, D. Equity in financing and use of health care in Ghana, South Africa, and Tanzania: Implications for paths to universal coverage. Lancet 2012, 380, 126-133. [CrossRef]

86. White, J. The 2010 US health care reform: Approaching and avoiding how other countries finance health care. Health Econ. Policy Law 2012, 8, 289-315. [CrossRef]

87. Sekhri, N.; Savedoff, W. Private health insurance: Implications for developing countries. Bull. World Health Organ. 2005, 83, 127-134.

88. Gu, X. Status and development of private health insurance in China. Insur. Stud. 2009, 11, $26-33$.

89. Zhao, B.; Dong, X.; Ma, X. Discussion on development strategies for Chinese commercial health insurance in the frame of new health reform. Insur. Stud. 2011, 2, 74-83.

90. Yetley, E.A.; MacFarlane, A.J.; Greene-Finestone, L.S.; Garza, C.; Ard, J.D.; Atkinson, S.A.; King, J.C. Options for basing Dietary Reference Intakes (DRIs) on chronic disease endpoints: Report from a joint US-/Canadian-sponsored working group. Am. J. Clin. Nutr. 2016, 105, 249S-285S. [CrossRef] [PubMed]

91. Liu, B.; Yan, H.; Guo, R.; Liu, X.; Li, X.; Xu, Y. The Basic Social Medical Insurance Is Associated with Clinical Outcomes in the Patients with ST-elevation Myocardial Infarction: A Retrospective Study from Shanghai, China. Int. J. Med Sci. 2014, 11, 905. [CrossRef]

92. Lam, K.K.; Johnston, J.M. Health insurance and healthcare utilisation for Shenzhen residents: A tale of registrants and migrants? Bmc Public Health 2012, 12, 868. [CrossRef]

93. Zhu, J.; Zhu, Y.; Liu, R. Health insurance of rural/township schoolchildren in Pinggu, Beijing: Coverage rate, determinants, disparities, and sustainability. Int. J. Equity Health 2008, 7, 23. [CrossRef] [PubMed]

94. Xu, Y.; Gao, J.; Zhou, Z.; Xue, Q.; Yang, J.; Luo, H.; Chen, G. Measurement and explanation of socioeconomic inequality in catastrophic health care expenditure: Evidence from the rural areas of Shaanxi Province. Bmc Health Serv. Res. 2015, 15, 256. [CrossRef]

95. Chen, M.; Chen, W.; Zhao, Y. New evidence on financing equity in China's health care reform-a case study on Gansu province, China. BMC Health Serv. Res. 2012, 12, 466. [CrossRef]

96. Chen, M.; Zhao, Y.; Si, L. Who pays for health care in China? The case of Heilongjiang province. PLoS ONE 2014, 9, e108867. [CrossRef] 
97. Xu, M. An analysis of determinants on health insurance demand in China-taking Shanghai' insurance market in 2006 as an example. >World Econ. Pap. 2007, 5, 30-40.

98. Zhu, M.; Wang, M. Tax Policy's Incentive Effects on Commercial Health Insurance. Insur. Stud. 2016, 2, $47-58$.

99. Yao, W.; Xiao, X.; Luo, C. Awareness and Utilization of Community Health Services and the Influencing Factors among Residents in Dongguan. Chin. Gen. Pract. 2012, 15, 3230-3232.

100. Li, M.; Yang, K.; Dong, Z. Study on the Needs, Demands and Utilization of Health Services: A Case Study of Sichuan Province. Reform Econ. Syst. 2016, 2, 41-46.

101. Wang, X.; Wang, H. Effect of basic medical insurance system on catastrophic health expenditure: A empirical study. Chin. J. Public Health 2017, 6, 9.

102. Li, X.; Qing, J.; Tang, J.; Chen, J.; Xu, D. Analysis of the Equity of Rural Family Health Financing in Xinjiang Province from 2003 to 2008. Mod. Prev. Med. 2012, 39, 875-877.

103. Liu, H.; Qin, J.; Chai, P.; Xu, D.; Liu, X.; Mao, L. Evaluation of Redistributive Effect of Health Financing in Xinjiang Production and Construction Corps. Chin. J. Health Stat. 2013, 30, 371-376.

(C) 2020 by the authors. Licensee MDPI, Basel, Switzerland. This article is an open access article distributed under the terms and conditions of the Creative Commons Attribution (CC BY) license (http://creativecommons.org/licenses/by/4.0/). 